\title{
Underground LoRa Sensor Node for Bushfire Monitoring
}

Ben Herring, School of Engineering and Built Environment, Griffith University, Brisbane, QLD 4222, Australia

Tony Sharp, Substation33, 31 Mary St, Kingston, QLD 4114, Australia

Tim Roberts, Jarred Fastier-Wooller, Greg Kelly, Oz Sahin, David Thiel, Dzung Dao and Peter L. Woodfield (i)*, School of Engineering and Built Environment, Griffith University, Brisbane, QLD 4222, Australia

Received: 29 September 2021/Accepted: 23 February 2022/Published online: 7 March 2022

\begin{abstract}
The feasibility of an underground LoRaWAN bushfire temperature sensing node from the point of view of survivability in a bushfire event is considered. Thermal penetration into the soil is modelled using a one-dimensional analytical formulation for a semi-infinite solid. A working prototype of the sensor unit was tested experimentally beneath a relatively small $(400 \mathrm{~mm} \times 400 \mathrm{~mm}$ base $)$ timber fire. A buried LoRa radio (depth $100 \mathrm{~mm}$ ) with a k-type thermocouple monitored the temperature from beneath the fire. The analysis demonstrates that under dry soil conditions, the time that the sensor node under the fire base can endure is proportional to the square of the depth of burial of the electronic components and inversely proportional to the thermal diffusivity of the soil. The original contribution of the work is in the practical demonstration of the durability of a LoRa sensing node beneath a fire front for bushfire sensing applications.
\end{abstract}

Keywords: Bushfire, LoRaWAN, Underground sensor, Temperature profile

\section{Introduction}

With the global increase in frequency and severity of bushfires [1], one of the major challenges is providing reliable information for making decisions to manage wildfire events: in particular the location of the fire front and forward spot fires. For this purpose, live data can be collected and collated from various sources including fire observation towers, satellite imagery [2-4], drone footage [5], social media [6], video image processing [7-9], lidar technology [10] and on the ground management by firefighters, and sensor networks [11]. No one technology can cover all bases completely and the different technologies have great potential to complement each other, improving the reliability of the data. For example, ground-based sensors can complement satellite sensing technology when cloud cover and smoke may interfere with defining the position and velocity of the fire

\footnotetext{
*Correspondence should be addressed to: Peter L. Woodfield, E-mail: p.woodfield@griffith.edu.au
} 
front. Multiple data sources can be integrated through machine learning algorithms $[12,13]$.

Among the options for automatic ground-level fire detection and monitoring, bushfire wireless sensor networks are showing promise as a technology emerging with the growth of the internet of things [14-19]. The challenges for bushfire sensors include the large land area to be monitored, the cost, the randomness of the time between fire events, false alarms, battery life, durability and surviving the fire event long enough to report meaningful data. LoRaWan technology promises to overcome some of these challenges since small sensors can be developed that are mass produced at low cost [20] with battery life more than five years [19]. Attenuation of radio communication through smoke and fire is also an important issue, as observed by Silvani et al. [21] and Li et al. [22]. Silvani et al. [21] observed that in addition to packet losses, time lags of 10 to $30 \mathrm{~s}$ in the radio network are a problem for fire experiments, offsetting cost savings over a directly wired approach.

Radio communication from buried sensors is an active area of research. Xuefen et al. [23] tested underground communication using LoRa and suggested that LoRa radio will be the support technology for the next generation of wireless underground sensor networks (WUSNs). Gineprini et al. [24] and showed that LoRaWAN can be used effectively for buried sensor applications. Di Renzone et al. [25] found that a soil depth of $100 \mathrm{~mm}$ had minimal impact on LoRaWAN transmission. In this study we demonstrate for the first time (to our knowledge), that surviving a fire event can be achieved through locating the electronic components of the LoRa node beneath the ground connected to a robust above-ground sensing element.

\section{Required Node Depth}

Thermal penetration into a homogeneous semi-infinite solid material is given by [26]:

$$
T(x, t)=T_{s}+\left(T_{i}-T_{s}\right) \operatorname{erf}\left(\frac{x}{2 \sqrt{\alpha t}}\right)
$$

where $T(x, t)$ is the temperature distribution below the surface, $T_{s}$ is the surface temperature, $T_{i}$ is the initial temperature of the soil, $x$ is the distance below the surface, $t$ is time and $\alpha$ is the thermal diffusivity of the soil. Equation (1) assumes that the initial temperature was uniform, and the surface temperature is constant.

A further merit of Eq. (1) is that it can be solved to give a form for deciding an appropriate penetration depth in relation to a Fourier number:

$$
\frac{\alpha t}{x^{2}}=F o_{r e q d}
$$


For the depth and time corresponding to $100^{\circ} \mathrm{C}$ where the surface is at $1100^{\circ} \mathrm{C}$ and the initial temperature at $25^{\circ} \mathrm{C}, F o_{\text {reqd }}=0.152$. This equation shows that the time of endurance is proportional to the square of the depth beneath the surface and inversely proportional to the thermal diffusivity. Equation (1) can be expressed in non-dimensional terms by shifting the temperatures to the left hand side. A Fourier number of 0.152 corresponds to a $7 \%$ reduction in the temperature difference between the initial and surface temperatures (i.e. the $75 \mathrm{~K}$ rise to reach $100^{\circ} \mathrm{C}$ is $7 \%$ of $1100-25 \mathrm{~K}$ ). Thus, for different initial and surface temperatures the change will still be $7 \%$ of the initial temperature difference, for the Fourier number of 0.152 .

The model given by Eqs. (1) and (2) does not take into account the soil moisture which will offer additional protection due to the latent heat of vaporization. A more comprehensive model for fire effects on soil was given by [27]. Figure 1 shows a comparison of Eq. (1) predictions with Campbell's experimental data for kiln-dried sand soil [27]. Their data for the same soil but with 14\% moisture at $35 \mathrm{~mm}$ below the surface is also included in the figure. As can be seen by comparing with the dry soil at $35 \mathrm{~mm}$ depth, the presence of moisture increases the soil diffusivity but ultimately delays the temperature rise during drying for $30 \mathrm{~min}$ at approximately $100^{\circ} \mathrm{C}$.

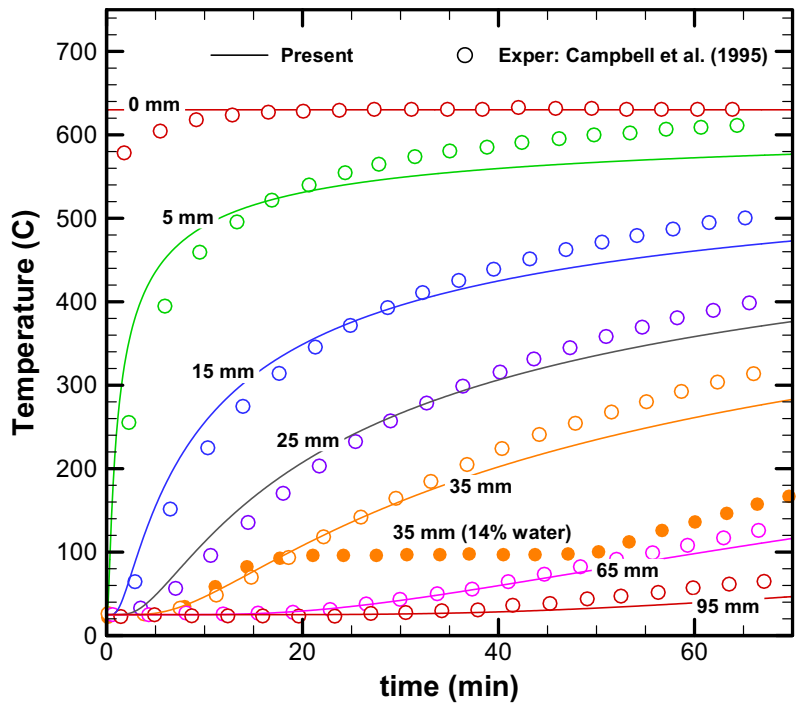

Figure 1. Transient temperature distribution beneath the surface of the soil calculated using Eq. (1) assuming the surface temperature is $630^{\circ} \mathrm{C}$ for $80 \mathrm{~min}$. Experimental data [27] correspond to kiln-dried Quincy sand soil from Washington. 


\section{Experimental Sefup}

Figure 2 gives a schematic of the experimental setup. The flame temperature sensor on the LoRa node is a k-type thermocouple supported by a stainless-steel tube containing $12 \mathrm{~mm}$ diameter ceramic beads to electrically insulate the chromel and alumel wires from each other. Silvani and Morandini, [28] also used a stainless steel tube with ceramic insulation for supporting thermocouples in their fire spread experiments. A nylon cable gland was used to connect the supporting pipe to the electronics container and prevent moisture leaking into the container. The LoRa radio in the sensor node wirelessly connects to a LoRaWAN gateway which is connected to the internet via a wifi router.

Before burying the sensor underground, six external k-type thermocouples (bead diameter $1 \mathrm{~mm}$ ) were attached to a stainless-steel support at $20 \mathrm{~mm}$ intervals between the top surface of the sensor container and the surface of the soil. Each of these thermocouples and a further thermocouple measuring ambient temperature, were connected to an 8-channel thermocouple data logger (Pico T08), which was then connected to a computer via USB. The reading of both the internal temperature and the thermocouple temperature measured by the LoRa node were recorded over the course of the experiment and downloaded from TheThingsNetwork.

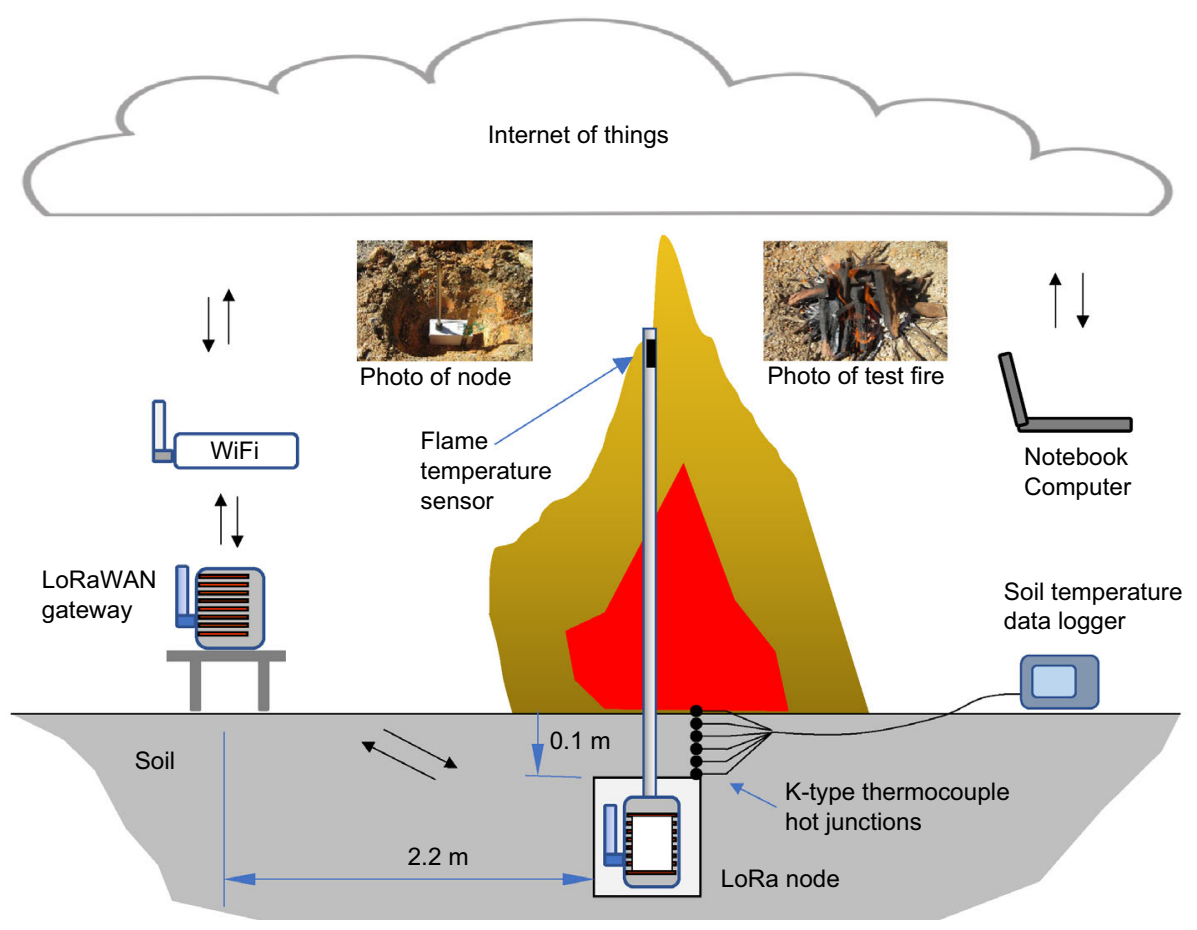

Figure 2. Experimental sełup. 
A sample of the soil between the node and the surface was collected and analyzed gravimetrically for moisture content using an oven at $105^{\circ} \mathrm{C}$ over $24 \mathrm{~h}$ to remove the moisture. The moisture content was $19.6 \%$.

The gateway was separated from the node by $2.2 \mathrm{~m}$ and a $400 \mathrm{~mm}$ diameter fire was constructed on the surface above and around the sensor. The node was buried under $100 \mathrm{~mm}$ of soil beneath the fire. The fire was lit, and the received and transmitted signals (temperature readings) over the course of a two-hour period was recorded. Transmission occurred at a frequency of one sample every $12 \mathrm{~s}$.

\section{Results}

Figure 3 shows the temperatures recorded during the experiment. The temperature at the surface (pink line) rapidly increased approaching a maximum temperature of $640^{\circ} \mathrm{C}$ after $74 \mathrm{~min}$. The maximum flame temperature measured was $760^{\circ} \mathrm{C}$. Whittaker [29] reviewed several works showing ground-level temperatures in the range from $210^{\circ} \mathrm{C}$ to $840^{\circ} \mathrm{C}$ suggesting the test fire temperatures are the correct order of magnitude to provide appropriate surface boundary conditions for the present bushfire simulation. The temperature measured inside the box housing the LoRa radio increased steadily and slowly from an initial temperature of $25^{\circ} \mathrm{C}$ to a maximum temperature of $53^{\circ} \mathrm{C}$ as the final reading. The fluctuations in temperature measured by the flame sensor are the result of variable wind conditions and the addition of more firewood to maintain the fire. The soil surface temperature

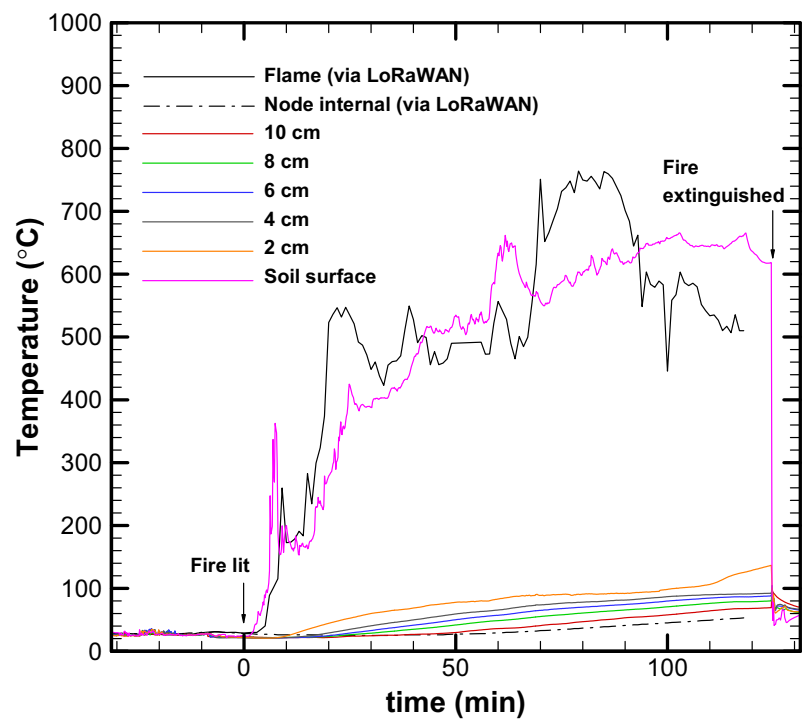

Figure 3. Temperature data collected during the fire experiment. The flame temperafure and infernal node temperature were transmitted via LoRaWAN. Soil temperature measurements were recorded using a datalogger as shown in Fig. 2. 
represents the temperature of the coals at the base of the fire and therefore was less affected by changes in wind conditions than the flame temperature sensor.

The subsurface temperatures (labeled as $20 \mathrm{~mm}$ to $100 \mathrm{~mm}$ in Fig. 3) show a steady increase during the period of the experiment with all measurements below $100^{\circ} \mathrm{C}$ for the first $90 \mathrm{~min}$ of the experiment. The change in trend for the temperature of the sensor at $2 \mathrm{~cm}$ depth after $110 \mathrm{~min}$ may be attributed to the soil moisture evaporating. A similar phenomenon can be seen in the experimental data by Campbell et al. [27] for 14\% moisture after 50 min as shown Fig. 1.

Overall, these measurements closely match the expected trend of heat conduction and the soil thermal penetration measurements of Bradstock and Auld [30] and Campbell et al. [27]. Increased depth reduced the rate of temperature increase with a maximum temperature of $69^{\circ} \mathrm{C}$ measured at $100 \mathrm{~mm}$ depth, compared to the $136^{\circ} \mathrm{C}$ measured at $20 \mathrm{~mm}$. These temperatures were higher than those measured by Bradstock and Auld [30] and lower than those measured by Campbell et al. [27] at the same depths and times. Each of these experiments had different fire temperatures, soil types and moisture contents, causing the differences in the results, however the present results seem reasonable for the conditions of the experiment.

The radio signal packet loss ratio during the test was $19 \%$. While this is high, tests done with the same setup and the same sensor node above the ground also showed $19 \%$ packet loss. For further confirmation, the radio transmission experiment was repeated for the node buried at depths from 0 to $200 \mathrm{~mm}$ with wet (23\% moisture) and damp (16\% moisture) soil without the fire as shown in Fig. 4. There was no clear trend against soil conditions, with packet losses ranging from 16 to $21 \%$ at a measurement distance $5 \mathrm{~m}$ from the node and $14 \%$ to $26 \%$ at $20 \mathrm{~m}$ from the node. Also, in the real application, the signal will be affected by trees, mountains and possibly smoke and other obstacles. Further tests should be done on the LoRa radio communication in bushland settings considering signal strength as well as packet loss.

The sensor node survived the fire conditions well. The stainless-steel pipe remained straight and was blackened by soot from the fire with no noticeable damage to the welded thermocouple. The buried PVC box housing the LoRa radio received only very mild warping on the top edge. The exposure to fire con-

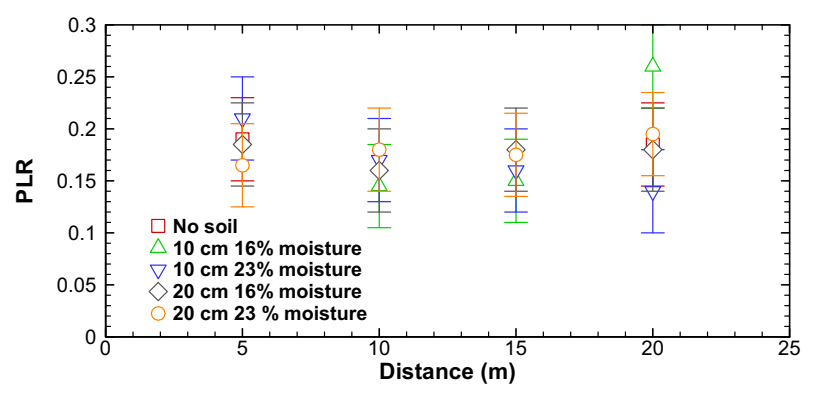

Figure 4. Packet Loss Ratio for different depths, soil moisture and horizontal distance. 
ditions in this experiment was long compared to the expected duration of 2-3 min for a fire front to pass as measured by Wotton et al. [31] in a dry Eucalypt Forest fire. The results are encouraging, as they suggest that the depth of operation will be suitable for resisting bushfire conditions. Alternatives to PVC with higher thermal resistance should be considered to make the node more robust.

\section{Conclusions}

In this study, a proposal as a part of a bushfire smart warning system was made to place a bushfire LoRaWAN sensor node underground to survive a bushfire event. Experiments were performed to verify the design of the bushfire sensor and to investigate LoRaWAN technology's performance. The device suffered no significant increase in signal loss under any of the conditions tested, including $100 \mathrm{~mm}$ of damp and wet soil and smoke and radiation interference from fires. This suggests that LoRaWAN is an effective technology for a bushfire warning system.

An analytical formulation was presented which demonstrates that under dry soil conditions, the time that the sensor node can endure is proportional to the square of the depth that the electronic components are placed beneath the surface and inversely proportional to the soil's thermal diffusivity. The presence of soil moisture increases the thermal protection of the node.

The proposed device has value for monitoring bushfires and for measuring fire conditions in bushfire research. To expand this work, future studies could consider the effect of fire and bushland on LoRa radio communication for multiple nodes with higher temperatures in a bushfire/controlled burn setting.

\section{Acknowledgements}

Support from Griffith University technical staff, J. Jardine and J. Webster for assisting with the experiments and from the Aus4Innovation/DFAT partnership grant is acknowledged gratefully.

\section{Funding}

Open Access funding enabled and organized by CAUL and its Member Institutions.

\section{Open Access}

This article is licensed under a Creative Commons Attribution 4.0 International License, which permits use, sharing, adaptation, distribution and reproduction in any medium or format, as long as you give appropriate credit to the original author(s) and the source, provide a link to the Creative Commons licence, and indicate if changes were made. The images or other third party material in this article are included in the article's Creative Commons licence, unless indicated 
otherwise in a credit line to the material. If material is not included in the article's Creative Commons licence and your intended use is not permitted by statutory regulation or exceeds the permitted use, you will need to obtain permission directly from the copyright holder. To view a copy of this licence, visit http://creat ivecommons.org/licenses/by/4.0/.

\section{References}

1. Finney MA (2021) The wildland fire system and challenges for engineering. Fire Safety J 120:103085

2. Giglio L, Schroeder W, Justice C (2016) The collection 6 MODIS active fire detection algorithm and fire products. Remote Sens Environ 178:31-41. https://doi.org/10.1016/ j.rse.2016.02.054

3. Hua L, Shao G (2017) The progress of operational forest fire monitoring with infrared remote sensing. J For Res 28(2):215-229

4. Chuvieco E, Aguado I, Salas J, García M, Yebra M, Oliva P (2020) Satellite remote sensing contributions to wildland fire science and management. Curr For Rep 6(2):8196

5. Yuan C, Zhang Y, Liu Z (2015) A survey on technologies for automatic forest fire monitoring, detection, and fighting using unmanned aerial vehicles and remote sensing techniques. Can J For Res 45(7):783-792

6. Slavkovikj V, Verstockt S, Van Hoecke S, Van de Walle R (2014) Review of wildfire detection using social media. Fire Saf J 68:109-118. https://doi.org/10.1016/j.firesaf.2014.05.021

7. Gaur A, Singh A, Kumar A, Kumar A, Kapoor K (2020) Video flame and smoke based fire detection algorithms: a literature review. Fire Technol 56(5):1943-1980

8. Zhou Z, Shi Y, Gao Z, Li S (2016) Wildfire smoke detection based on local extremal region segmentation and surveillance. Fire Saf J 85:50-58

9. Matthews S, Sullivan A, Gould J, Hurley R, Ellis P, Larmour J (2012) Field evaluation of two image-based wildland fire detection systems. Fire Saf J 47:54-61

10. Fernandes AM, Utkin AB, Lavrov AV, Vilar RM (2006) Optimisation of location and number of lidar apparatuses for early forest fire detection in hilly terrain. Fire Saf $\mathbf{J}$ 41(2):144-154

11. Hristov G, Raychev J, Kinaneva D, Zahariev P (2018) Emerging methods for early detection of forest fires using unmanned aerial vehicles and Lorawan sensor networks. In: 2018 28th EAEEIE annual conference (EAEEIE) (pp 1-9)

12. Abid F (2021) A survey of machine learning algorithms based forest fires prediction and detection systems. Fire Technol 57:559-590

13. Baek J, Alhindi TJ, Jeong YS, Jeong MK, Seo S, Kang J, Choi J, Chung H (2021) Real-time fire detection algorithm based on support vector machine with dynamic time warping kernel function. Fire Technol 1-25

14. Antunes M, Ferreira LM, Viegas C, Coimbra AP, de Almeida AT (2019) Low-cost system for early detection and deployment of countermeasures against wild fires. In: 2019 IEEE 5th world forum on internet of things (WF-IoT), pp 418-423

15. Azevedo BF, Brito T, Lima J, Pereira AI (2021) Optimum sensors allocation for a forest fires monitoring system. Forests 12(4):453

16. Luna P, Gutiérrez S, Espinosa R (2020) Design and implementation of a node geolocation system for fire monitoring through LoRaWAN. In: 2020 IEEE international autumn meeting on power, electronics and computing (ROPEC), vol 4, pp 1-6 
17. Sasmita ES, Rosmiati M, Rizal MF (2018) Integrating forest fire detection with wireless sensor network based on long range radio. In: IEEE international conference on control, electronics, renewable energy and communications (ICCEREC), pp 222-225

18. Sendra S, García L, Lloret J, Bosch I, Vega-Rodríguez R (2020) LoRaWAN network for fire monitoring in rural environments. Electronics 9(3):531

19. Vega-Rodríguez R, Sendra S, Lloret J, Romero-Díaz P, Garcia-Navas JL (2019) Low cost LoRa based network for forest fire detection. In: IEEE sixth international conference on internet of things: systems, management and security (IOTSMS), pp 177-184

20. Rizanov S, Stoynova A, Todorov D (2019) System for early warning and monitoring of wildfires. In: 2019 IEEE XXVIII international scientific conference electronics (ET), pp $1-3$

21. Silvani X, Morandini F, Innocenti E et al (2015) Evaluation of a wireless sensor network with low cost and low energy consumption for fire detection and monitoring. Fire Technol 51:971-993

22. Li Y, Yuan H, Lu Y et al (2017) Experimental studies of electromagnetic wave attenuation by flame and smoke in structure fire. Fire Technol 53:5-27

23. Xue-fen W, Xing-jing D, Yi Y, Jing-wen Z, Sardar MS, Jian C (2017) Smartphone based LoRa in-soil propagation measurement for wireless underground sensor networks. In: 2017 IEEE conference on antenna measurements \& applications (CAMA). IEEE, pp 114-117

24. Gineprini M, Parrino S, Peruzzi G, Pozzebon A (2020) LoRaWAN performances for underground to aboveground data transmission. In: 2020 IEEE international instrumentation and measurement technology conference (I2MTC), pp 1-6

25. Di Renzone G, Parrino S, Peruzzi G, Pozzebon A, Bertoni D (2021) LoRaWAN underground to aboveground data transmission performances for different soil compositions. IEEE Trans Instrum Meas 70:1-13. https://doi.org/10.1109/tim.2021.3061820

26. Carslaw HS, Jaeger JC (1992) Conduction of heat in solids. Clarendon press

27. Campbell GS, Jungbauer JD Jr, Bristow KL, Hungerford RD (1995) Soil temperature and water content beneath a surface fire. Soil Sci 159(6):363-374

28. Silvani X, Morandini F (2009) Fire spread experiments in the field: temperature and heat fluxes measurements. Fire Saf J 44(2):279-285

29. Whittaker E (1961) Temperatures in heath fires. J Ecol 49(3):709. https://doi.org/ $10.2307 / 2257233$

30. Bradstock R, Auld T (1995) Soil temperatures during experimental bushfires in relation to fire intensity: consequences for legume germination and fire management in SouthEastern Australia. J Appl Ecol 32(1):76. https://doi.org/10.2307/2404417

31. Wotton BM, Gould JS, McCaw WL, Cheney NP, Taylor SW (2011) Flame temperature and residence time of fires in dry eucalypt forest. Int J Wildl Fire 21(3):270-281

Publisher's Note Springer Nature remains neutral with regard to jurisdictional claims in published maps and institutional affiliations. 